\title{
Analysis on the characteristics of energy mix in Myanmar
}

\author{
Lei Xiangyang ${ }^{1,2 a}$, Wu Youde ${ }^{3}$ \\ ${ }^{1}$ Department of Geography, Yunnan Normal University, Kunming, 650092 \\ ${ }^{2}$ Southwest China Geographical Environment and Frontier Developmental and Collaborative Innovation Centre of Yunnan Province, \\ Yunnan Normal University, Kunming, 650092 \\ ${ }^{3}$ Myanmar Research Centre, Yunnan Normal University, Kunming, 650092
}

\begin{abstract}
Energy has been a key factor in economic development. Myanmar has considerable indigenous energy potential, which could meet domestic demand in long term if properly managed. This paper documents the current status of energy demand and supply in Myanmar, and analyses the characteristics of energy mix, and concludes that (1) Myanmar is confronted with a pressing energy demand with the rapid development of economy; (2) Myanmar's energy production mix is dominated by oil, gas and hydropower, and the consumption structure is dominated by biomass; (3) the shortage of energy is mostly due to its unbalanced energy mix and irrational notion for energy utilization. In order to solve the serious problems between energy demand and supply, it is necessary for Myanmar to build more responsible hydropower projects, to optimize the national grid and to make more reliable and practicable energy plans.
\end{abstract}

\section{Introduction}

Energy is a crucial factor which indicates the development level of economy [1]. As for energy consumption, most scholars believe that it has a longterm or short-term positive influence on economic growth [2-4]. Energy acts as an engine forcefully driving the world's economy forward.

Myanmar is located in Southeast Asia, with a total population of 51,486,253 (2014 Census), of which about $70 \%$ resides in rural areas [5]. Due to the democratic transition in 2011, the condition of Myanmar is getting more favourable after over five decades of military rules. With a good endowment of natural resources, Myanmar becomes a charming investment destination. Myanmar maintains a high speed of economy growth about $7 \%$, ranked the ninth among the world's fastest growing economies [6].

According to the criteria set by the Department of Economic and Social Affairs, United Nations, Myanmar is still one of the least developing countries around the world due to a fifty-year-old military regime and nearly thirty years of isolation. Given the fact that energy is a basic requirement for a nation to grow independently, Myanmar policymakers are struggling to fill the gap in growing energy demand. Undoubtedly, energy conservation in Myanmar plays an important role in upgrading its economic status. However, despite sitting on huge energy resources, Myanmar's potential is severely constrained by limited energy infrastructure.

Peculiarly, although Myanmar is abundant in natural gas and crude oil, it still imports oil from other countries. The tremendous gap between energy supply and demand in Myanmar severely restricted economic and social development and slowed down the rate of economic growth. Energy shortage becomes a bottleneck for Myanmar's further development.

\section{Methods and data}

A quantitative analysis method was employed in this study. The data in this study were collated from the previous published research papers, articles, reports from Myanmar Ministry of Energy, the Myanmar Statistic Yearbook of 2019, and the Myanmar Energy Master Plan of 2015.

\section{The current status of energy mix in Myanmar}

\subsection{Energy types}

During the period of democratic transition, Myanmar opened up its doors and ushered in a development opportunity. Myanmar is endowed with vast energy resources ranging from coal, natural gas, crude oil, and hydropower. In terms of reserves, Myanmar has a large amount of energy resources. It has potential reserves of 15220.27 million barrels of crude oil, 166.13 trillion cubic feet of natural gas, 711 million metric tons of coal and 108,000 megawatts of hydropower [7]. Nevertheless, there is a huge gap between the potential reserve and identified reserve because of both technical and fund deficiency.

In spite of the fact that Myanmar is among the world's oldest oil-producing countries, the country remains a net importer of oil for lack of oil-refinery

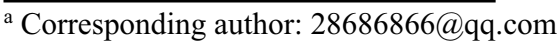


facilities. Its proven natural gas reserves of $300 \mathrm{BCM}$, which ranks Myanmar in 34th position globally. The reserve is totally unremarkable from a global perspective because the reserve is accounted for only $0.2 \%$ of total world gas reserves [8]. However, its position is much more significant regionally. Myanmar is one of the five major energy exporters in Southeast Asia, particularly of natural gas. Myanmar exported 8.81 billion cubic meters (BCM) of natural gas in 2010, significantly more than Malaysia (1.45 BCM) and second only to Indonesia $(9.89 \mathrm{BCM})$. It has guaranteed the energy sustainability and security of this region. This also attracts foreign investment to flow in Myanmar. According to the Directorate of Investment and Company Administration, nearly one third of the country's $\$ 74.045$ billion in foreign direct investment is in the oil and gas sector, and another one third is in electricity (as of March 2020).

Myanmar has the potential of hydropower estimated to be more than 100,000 megawatts (MW), but only $2 \%$ has been developed. The Myanmar Statistic Yearbook of 2019 indicates Myanmar's current installed capacity is 5651 Megawatts.

Biomass is a major renewable source in Myanmar since its economy is agriculture-based and has a high rate of around $50 \%$ of forest cover.

Fossil fuels such as oil, gas, coal etc. are not renewable and increase global warming. Economic growth is linked to energy consumption, with fossil fuel energy inevitably emitting $\mathrm{CO}_{2}$ that pollutes the environment. In recent years, Myanmar has strived to promote the use of renewable energy sources, namely hydropower, biomass energy, solar energy, wind energy, geothermal energy, tidal power and etc.

\subsection{Energy demand and supply}

Myanmar has various types of energy supply, yet the country's energy utilization is unreasonable. The demand for energy is strong, but the supply is weak and it is difficult to meet the needs for economic and social development. The enormous gap between energy demand and supply results in serious energy shortage in most sectors. With the lowest electric power coverage in Southeast Asia, Myanmar struggles in the urgent need for electricity as its urban population density ranks second the Southeast Asia. Of the national electricity demand, $94 \%$ is supplied by the national grid, and the other $6 \%$ is supplied by independent small power station transmission outside the grid. Currently, only $56 \%$ of the population have access to electricity. According to the Myanmar Ministry of Statistics, till the end of 2015 Myanmar's electric power had been mainly supplied by hydropower, natural gas and coal, accounting for $67 \%$, $28 \%$ and $3 \%$ respectively, while wind power, solar power, and biomass power accounted for $2 \%$, see table 1 .

Table 1. Electricity supply by type in 2015

\begin{tabular}{|c|c|c|c|c|c|c|}
\hline Type & Hydro & Gas & Coal & Solar & Wind & Biomass \\
\hline Percentage & $67 \%$ & $28 \%$ & $3 \%$ & \multicolumn{4}{|c|}{$2 \%$} \\
\hline
\end{tabular}

According to the National Power Expansion Plan of Myanmar, the power mix will be $24 \%$ gas, $10 \%$ coal, $50 \%$ hydro, $12 \%$ renewable and $4 \%$ imports in 2030 , see table 2 .

Table 2. Electricity supply by type in 2030

\begin{tabular}{|c|c|c|c|c|c|}
\hline Type & Hydro & Gas & Coal & Renewable & Imports \\
\hline Percentage & $50 \%$ & $24 \%$ & $10 \%$ & $12 \%$ & $4 \%$ \\
\hline
\end{tabular}

\subsection{Energy consumption}

Traditional energy such as fuel wood, charcoal and biomass are the main sources in Myanmar's energy consumption mix because it is an agricultural economy in nature. Among the major renewable energy sources, hydropower plays a key role in electrification of Myanmar while biomass provides the major energy supply for cooking and heating in rural areas. Figure 1 shows the components of Energy consumption: biomass, the largest energy source in Myanmar, covers over $60 \%$ of the total energy sources. Crude oil and petroleum product accounts for $13.45 \%$, then, natural gas, $10.67 \%$, hydropower, $9.55 \%$ and coal and lignite, $2.48 \%$.

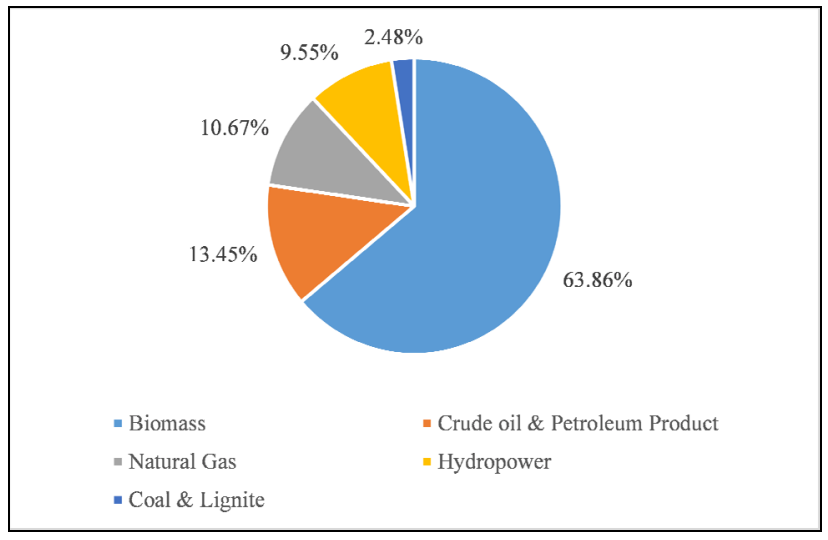

Fig. 1. Primary Energy Sources in Myanmar.

Myanmar has considerable indigenous energy potential, which could meet domestic demand in long term if properly planed. In terms of the utilization rate, Myanmar's energy supply is far from sufficient. Fossil fuels such as oil, gas and coal are not renewable and increase global warming and are unfriendly to the environment. Energy consumption is an important indicator to measure the progress of economic development. Myanmar has a tendency towards extreme environmentalism that is specifically manifested as the resistance on fossil fuel as well as hydropower and the advocacy of renewable energy sources, namely biomass energy, solar energy, wind energy, geothermal energy and tidal power. 


\section{The characteristics of energy mix in Myanmar}

\subsection{Rapid growth in demand}

With the rapid development of economy, Myanmar is confronted with a pressing need for energy, especially electricity. The forecast of electricity demand is shown in figure 2.

Myanmar sets the goal of $100 \%$ electrification in 2030. Nevertheless, there is a cliff-like distance from the current installed capacity to that of 24,981 megawatts in 2031. To achieve this goal, an average annual increase of about 1,700 megawatts is required. By 2030, Myanmar's target of installed capacity is nearly 3 times the current size. This is a thorn path to go, especially affected by 2019-NCOV in 2020 and the military takeover in February, 2021. Some foreign investment withdrew for fear of high risks.

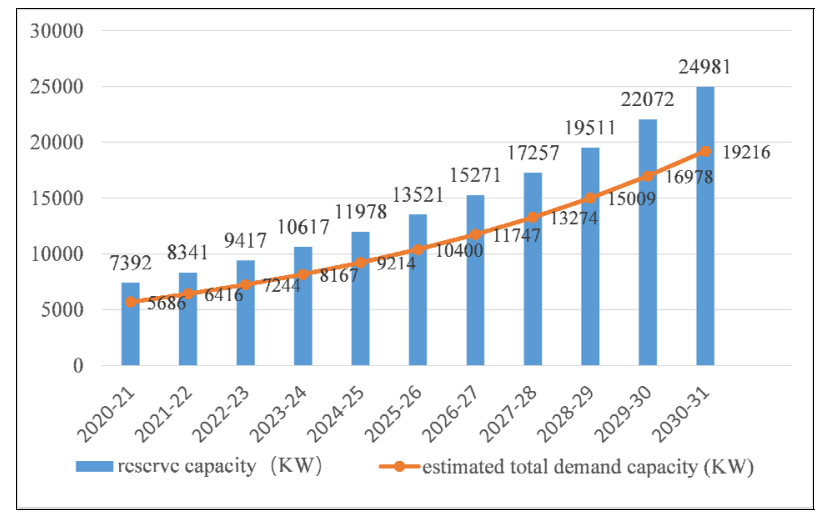

Fig. 2 The forecast of electricity demand

\subsection{Serious energy shortage}

Currently nearly half of the population is still deprived of access to electricity. It is pitiful to live in the poor mire of energy-poverty in such a favourable situation of energy sources. Because of energy poverty, factories and commercials are in the danger of shutting down. Low utilization rate of resources makes energy shortage more serious. Myanmar's potential is underdeveloped because the Burmese prefer solar energy or wind energy to hydropower. Despite of low cost of hydropower, largescale hydropower projects are opposed by local villagers in Myanmar on the ground of unfriendliness to the environment. From the perspective of infrastructure, two reasons account for the shortage of electricity: one is the weak capacity for supply, and the other is that Myanmar's weak national power grid is seriously aging, causing great loss of power. Institutionally, the malformed electricity price system deepens the crisis of energy shortage. For a long time, the Myanmar government has subsidized electricity prices, which results in long-term and serious losses for power companies. This is caught in a vicious circle: the more electricity is consumed, the more cost the power company pays. Therefore, electricity price reforms should be on the top priority.

\subsection{Unbalanced supply structure of energy}

The generation mix in Myanmar is dominated by hydropower, oil and gas, while the consumption structure is dominated by biomass. Given the fact that Myanmar is still in in the World Bank's least developed nation category, biomass energy still accounts for half of the consumption structure for a long time, in the form of firewood and husk of rice for household cooking and heating. Although Myanmar is an agricultural economy and agriculture takes the lion's share of GDP, the consumption of energy by this sector is really low, only $2 \%$, see figure 3 .

From figure 3 , the sector of residential-rural consumes $58 \%$ of energy, and the sector of commercial and the transport consume $13 \%$ and $11 \%$ respectively in Myanmar's energy consumption mix. We also can see that industry consumes $6 \%$ of energy, which indicates the development level of industry in Myanmar is quite low.

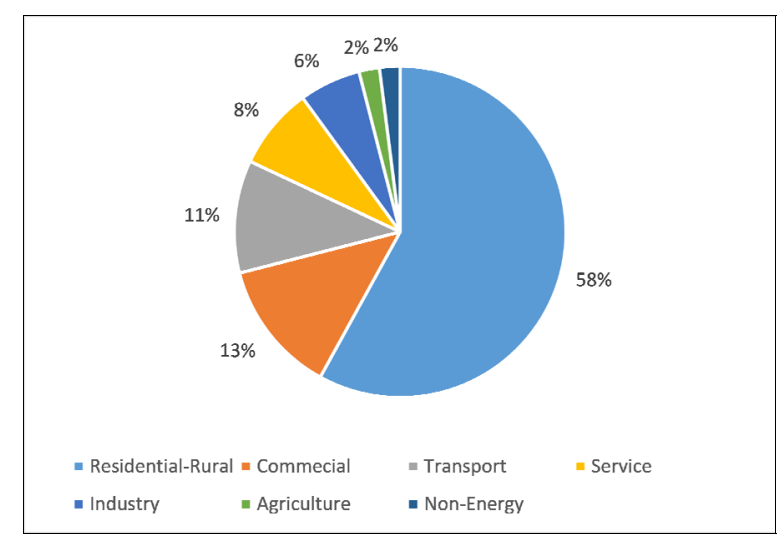

Fig. 3 Energy consumption by sector

\section{The future trend and policy implications}

In the light of the standards set by the UN Department of Economic and Social Affairs, Myanmar remains one of the poorest countries in the world. The democratic transition in 2011 accelerated Myanmar's development, both economically and socially. Myanmar is no longer isolated and sanctioned by the West. Abundant natural resources and considerable young labour force have brought new development opportunities to Myanmar. Considering that electricity is a basic requirement for a country's independent development, Myanmar will invest more fund on energy production and optimize energy mix in the future. In order to achieve the goal of $100 \%$ electrification in 2030, hydropower, a clean and renewable energy, needs vigorous development. In contrast to fossil-fuel sources, such as gas, oil and coal, hydropower offers low-carbon energy generation, lowcost power generation, and important potential and more friendly to the environment. As renewable energy, hydropower has obvious advantages over solar and wind power. It is more reliable, low-cost, and has an important potential for energy storage and peaking supply. Nevertheless, it is worth noting that, on the one hand, 
Myanmar has an urgent demand for electricity and it indeed has the great potential of hydropower. On the other hand, hydropower, especially large-scale hydropower projects are often resisted by local villagers. The suspension of China-Myanmar Myitsone dam causes great loss to both countries and discourages foreign investors.

The second trend is to optimize the national grid. As far as the current situation is concerned, the power grid is also an important factor in energy shortages. The rate of electrification in each state or division differs from another. Yangon Division has the highest rate of electrification of $78 \%$, Kayar State ranks the second, with the rate of electrification of $46 \%$, Mandalay Division ranks the third, $40 \%$, and the capital city Nay Pyi Taw has a rate of 39\%. Myanmar's grid status brings good investment opportunities for foreign-funded enterprises. Power grid projects have the advantages of low investment, low risk, short construction period and quick return on earnings.

The third trend is to make more reliable and practicable energy plans. Undoubtedly the consumption of energy in Myanmar plays an important role in improving its economic status. The Myanmar Energy Master Plan of 2015 indicates that national consumption of coal is expected to increase, while natural gas in the power sector is expected to decrease to meet increased demand for electricity over the period 2015-2030. This demonstrates that the Myanmar government hurries to achieve $100 \%$ electrification goal because coal plants have short construction period. However, coal reserve in Myanmar has little advantages over other renewable resources in the long term whereas the cost is high, and furthermore, results in great environmental problems. At present, conflicting understandings at the government level limit the implementation of power development plans. Some people demand the abandonment of hydropower and thermal power. They insist that these two types of renewable energy have a large environmental impact, and unrealistically claim that energy independence can be achieved through solar energy.

\section{Conclusion}

It is concluded that Myanmar's energy production mix is dominated by oil, gas and hydropower, and the consumption structure is dominated by biomass. The shortage and mismatch between production and consumption are long-standing problems in Myanmar energy development. Policy-makers in Myanmar are endeavouring to employ various approaches to overcome energy poverty. In recent years, the Myanmar government has vigorously attracted foreign investment for the exploitation of its energy resources. The current China-Myanmar Economic Corridor, which focuses on energy cooperation, has brought opportunities for Myanmar's energy development. Different types of projects including the exploitation of wind and solar power are underway. It is about to mitigate the current situation to a certain extent. There are broad prospects for China and Myanmar on energy cooperation, and clean energy such as hydropower, solar energy and wind energy will be the focus of cooperation in the future.

\section{Acknowledgments}

This research was funded by the project NSSFC (Grant No.16ZDA041), the Fundamental Research Funds for the Southwest China Geographical Environment and Frontier Developmental and Collaborative Innovation Centre of Yunnan Province.

\section{References}

1. N. N. Aye., T. Fujiwara, Glob. J. Flex. Syst. Manag. 15, 3 (2014)

2. M. J.Alam, I. A. Begum, J. Buysse, G. Van Huylenbroeck, Energy Policy. 45 (2012)

3. K Fatai, L. Oxley, F.G. Scrimgeour, Math. Comput. Simul. 64, 3-4 (2004)

4. Ch.-Ch. Lee, Ch.-P. Chang, Energy Econ. 27, 6 (2005)

5. S. Ahmed, K. Alam, A.Rashid, J. Gow, Defence Peace Econ. 31, 6 (2019)

6. M. M. Tun, Eur. J. Sustain. Dev. Res. 3,1 (2019)

7. B. K. Sovacool, Energy Sustainable Dev. 17, 4 (2013)

8. W. W. Kyaw, S. Sukchai, N. Ketjoy, S. Ladpala, Energy Procedia. 9 (2011) 